\title{
LAS VIOLENCIAS MACHISTAS EN LAS TRAYECTORIAS VITALES DE MUJERES MIGRANTES
}

\section{MALE VIOLENCE IN THE LIFE TRAJECTORIES OF MIGRANT WOMEN}

\author{
Gabriela Moriana Mateo \\ Universidad de Valencia. Valencia/España \\ gabriela.moriana@uv.es
}

Recibido/Received: 12/01/2018

Modificado/Modified: 15/08/2018

Aceptado/Accepted: 10/09/2018

\section{RESUMEN}

Esta aproximación presenta parte de los resultados de un trabajo de campo etnográfico realizado en distintos centros de protección de mujeres de la Comunidad Valenciana. Su objetivo es conocer los tipos de violencia que han sufrido las mujeres migrantes institucionalizadas desde su perspectiva y punto de vista. La metodología utilizada es de índole cualitativa. Así, a través de la observación participante, documentos personales, informes sociales y, sobre todo, entrevistas en profundidad e informales, se han elaborado 15 historias de vida, 6 de ellas de mujeres migrantes. Respecto a los resultados, en las trayectorias vitales de las mujeres migrantes institucionalizadas subyace que han sufrido distintos tipos de violencia en su familia de origen cuando eran menores y de género e institucional siendo menores y mayores de edad. Una de las principales conclusiones es que lo que las convierte en vulnerables a las violencias machistas es la pobreza y la exclusión social.

\section{PALABRAS CLAVE}

Migración; vulnerabilidad; violencia contra las mujeres; institucionalización; interseccionalidad.

\section{SUMARIO}

1. Introducción. 2. Material y método. 3. Resultados. 4. Discusión. 5. Conclusiones. Bibliografía.

\begin{abstract}
This paper presents some of the results from ethnographic fieldwork carried out in different women's shelters in the Valencia Autonomous Community. The aim was to find out the types of violence suffered by institutionalized migrant women, from their perspective and point of view. The study follows a qualitative methodology. Based on participant observation, personal documents, social reports and, especially, in-depth informal interviews, 15 life stories were compiled, 6 of which were for migrant women. The results show that underlying the life trajectories of these institutionalized migrant women is the fact that they suffered various types of violence in their families of origin when they were minors, and gender-based and institutional violence both as minors and adults. One of the main conclusions is that what makes these women vulnerable to male violence is poverty and social exclusion.
\end{abstract}

\section{KEYWORDS}

Migration; Vulnerability; Violence against Women; Institutionalization; Intersectionality. 


\section{CONTENTS}

1. Introduction. 2. Materials and method. 3. Results. 4. Discussion. 5. Conclusions. References.

\section{INTRODUCCIÓN}

La violencia contra las mujeres es un fenómeno universal e histórico que afecta a las mujeres de todas las clases sociales y edades. Aunque, no de igual manera y con la misma brutalidad. La especial vulnerabilidad de algunos grupos o colectivos, tal es el caso de las mujeres migrantes, ha sido señalada en diversos documentos internacionales, como la Declaración sobre la Eliminación de la Violencia contra la Mujer (1993) y la IV Conferencia Mundial sobre la Mujer (1995) de Naciones Unidas (ONU).

Así, si bien las mujeres españolas comparten con las migrantes el riesgo de sufrir violencia de género, la proporción de estas últimas que en el Estado español dicen sufrirla, la denuncian o son asesinadas por sus parejas o exparejas supone una sobrerrepresentación respecto a su peso demográfico (Macroencuesta, 2015; IX Informe del Observatorio Estatal de Violencia sobre la Mujer, 2015).

Así mismo, las mujeres inmigrantes residentes en la Comunidad Valenciana que son asesinadas por sus parejas o exparejas, denuncian la violencia de género y son atendidas en los recursos específicos de violencia: Centros 24 Horas y centros de protección de mujeres, también están sobrerrepresentadas respecto a la proporción de mujeres residentes (Moriana, 2014).

El tema de investigación que nos ocupa tiene que ver tanto con mi compromiso personal y profesional, como con su gravedad. El argumento central de este artículo, elaborado en base a los resultados de mi tesis doctoral, analiza el binomio violencia machista y uno de los colectivos que la sufren muy duramente, las mujeres migrantes.

\section{MATERIAL Y MÉTODO}

En primer lugar y con el objetivo de partir de un marco teórico común de interpretación y análisis, se van a abordar las principales definiciones normativas de violencia contra las mujeres y las niñas. Posteriormente, se abordará el enfoque metodológico, cuya índole es cualitativa.

\subsection{Definiendo la violencia contra las mujeres y las niñas}

La Declaración de la Eliminación de la Violencia contra la Mujer de la ONU (1993), entiende por violencia contra la mujer "todo acto de violencia basado en la pertenencia al sexo femenino que tenga o pueda tener como resultado un daño o sufrimiento físico, sexual o psicológico para las mujeres, así como las amenazas de tales actos, la coacción o la privación arbitraria de la libertad, tanto si se producen en la vida pública como en la vida privada".

Se trata de una definición amplia que, sin ser excluyente, señala tres tipos de violencia contra las mujeres: física, psíquica y sexual y tres ámbitos donde se produce: la familia, la comunidad en general y la perpetrada o tolerada por el estado. Así, podemos considerar que tanto la omisión de la ayuda a las mujeres y niñas para que puedan escapar de la violencia como la falta de protección son violencias institucionales, en el sentido de permitidas o toleradas por el Estado. 
Por su parte y centrándonos en el ámbito estatal, la Ley Orgánica 1/2004, de 28 de diciembre, de Medidas de Protección Integral contra la Violencia de Género, tiene por objeto actuar contra la violencia que, como manifestación de la discriminación, la situación de desigualdad y las relaciones de poder de los hombres sobre las mujeres, se ejerce sobre éstas por parte de quienes sean o hayan sido sus cónyuges o de quienes estén o hayan estado ligados a ellas por relaciones similares de afectividad, aun sin convivencia. La violencia de género a que se refiere esta ley comprende todo acto de violencia física y psicológica, incluida las agresiones a la libertad sexual, las amenazas, las coacciones o la privación arbitraria de libertad.

En las Comunidades Autónomas se ha optado por definiciones más amplias. Así, Ley 7/2012, de 23 de noviembre, de la Generalitat, Integral contra la Violencia sobre la Mujer en el ámbito de la Comunitat Valenciana, señala, sin carácter excluyente, la violencia física, psicológica, sexual, económica (toda aquella limitación, privación no justificada legalmente o discriminación en la disposición de sus bienes, recursos patrimoniales o derechos económicos, comprendidos en el ámbito de convivencia de la pareja o en los casos de ruptura de la relación), la mutilación genital femenina y otras prácticas tradicionales y/o culturales nocivas o perjudiciales para las mujeres y niñas.

En relación a las y los menores, la Convención de los Derechos de los Niños de la Organización de Naciones Unidas (ONU, 1989) entiende que el maltrato infantil es "toda forma de perjuicio o abuso físico o mental, descuido o trato negligente, malos tratos o explotación, incluido el abuso sexual, mientras el niño se encuentre bajo la custodia de los padres, de un representante legal o de cualquier otra persona que lo tenga a su cargo".

En último lugar, para el Ministerio de Trabajo y Asuntos Sociales (2006), los malos tratos a la infancia son "la acción, omisión o trato negligente, no accidental, que priva al niño o la niña de sus derechos y su bienestar, que amenaza y/o interfiere su ordenado desarrollo físico, psíquico y/o social y cuyos autores pueden ser personas, instituciones o la propia sociedad".

\subsection{La investigación feminista interseccional y la metodología cualitativa}

Tanto la estrategia general como las más importantes técnicas de investigación utilizadas en este trabajo han sido de índole cualitativa. Una de las más importantes justificaciones de su uso es conocer la interpretación que las personas investigadas hacen de la realidad, su valoración y percepción (Hernández Pedreño, 2008). Se reconocen dos perspectivas dentro del enfoque cualitativo, una interpretativa y otra crítica (Tójar, 2006). La mirada feminista es una mirada crítica de la sociedad (Del Valle, 2012). El paradigma feminista concibe la realidad desde la perspectiva de género y lucha contra el sistema de estratificación sexo/género que posibilita la histórica dominación de las mujeres. Este enfoque es esencial para la ciencia, porque introduce la crítica al sesgo androcéntrico presente en el análisis social. Por ello, podemos decir que el género, como categoría analítica, da forma y significado a las relaciones de poder (Scott, 2003; Izquierdo, 2004). La teoría feminista y la investigación cualitativa se enriquecen mutuamente. La primera, aporta nuevas miradas a la investigación cualitativa y ésta mejora la investigación feminista con sus métodos y técnicas.

Pero además, esta investigación incorpora la mirada interseccional, porque en el contexto de la violencia contra las mujeres, este enfoque permite visibilizar, identificar y analizar cada situación específica y particular en la que se encuentra las mujeres sujetos de estudio, en las que además de sufrir violencia machista, se solapan otras realidades de desigualdad como la clase social, la etnia (pero también la edad, enfermedad, diversidad funcional y la opción sexual, etc.) que da como resultado una mayor vulnerabilidad.

La investigación que se presenta es fruto de un trabajo de campo etnográfico realizado en 
distintos centros de protección de mujeres de la Comunidad Valenciana. Formó parte de mi doctorado en estudios de género y constituyó la base de mi tesis doctoral sobre los tipos de violencia y procesos de exclusión social que sufren las mujeres institucionalizadas.

Dicha investigación fue posible desde 1999 hasta 2012 gracias a mi experiencia laboral en diferentes centros de acogida de mujeres de la Comunidad Valenciana, en los que convertí el espacio profesional en objeto de estudio. En puridad metodológica, no se puede hablar de selección de casos, sino, más bien, de intentos continuados de conseguir relatos de vida de las mujeres residentes en los centros de protección. Es muy difícil que hablen, hay mucho dolor, no conocen a las profesionales y desconfían de la institución. Por ello, se trata de una información dificilísima de conseguir y de un valor inconmensurable.

Siguiendo a Pujadas (1992), el enfoque biográfico puede utilizar tres tipos de narrativas diferentes: relatos de vida (biografías tal y como son contadas por los narradores), biogramas (registros biográficos de un amplio número de biografías personales) e historias de vida (reconstrucciones biográficas a través de relatos y otras fuentes complementarias). Este último tipo de narrativa se ha utilizado en esta investigación. Así, las historias de vida se han elaborado con el material obtenido de los relatos de las mujeres (conseguido a través de entrevistas biográficas) y de otra información sobre sus vidas (informes sociales $\mathrm{y}$ documentos personales); por su parte, la observación participante durante todo el proceso, ha permitido tanto completar la información, como verificar y dar fiabilidad a los resultados. Seguidamente se expone la relación de las historias de vida de las mujeres migrantes institucionalizadas en los centros de protección de la Comunidad Valenciana.

Cuadro 1. Relación de las historias de vida de las mujeres migrantes institucionalizadas en distintos centros de protección de mujeres de la Comunitat Valenciana.

\begin{tabular}{|c|l|c|c|}
\hline $\begin{array}{c}\mathrm{N}^{\circ} \text { HISTORIA DE } \\
\text { VIDA }\end{array}$ & $\begin{array}{c}\text { PAÍS DE } \\
\text { PROCEDENCIA }\end{array}$ & $\begin{array}{c}\text { AÑO } \\
\text { NACIMIENTO }\end{array}$ & $\begin{array}{c}\mathrm{N}^{\circ} \\
\text { HIJAS/OS }\end{array}$ \\
\hline (HV1) & Guinea & 1983 & 2 \\
\hline (HV2) & Brasil & 1977 & 2 \\
\hline (HV3) & Bolivia & 1878 & 3 \\
\hline (HV4) & Marruecos & 1983 & 1 \\
\hline (HV5) & Rumania & 1976 & 2 \\
\hline (HV6) & Colombia & 1981 & 2 \\
\hline
\end{tabular}

Fuente: elaboración propia

\section{RESULTADOS}

Respecto a los resultados, cabe señalar que, en las historias de vida de las mujeres migrantes institucionalizadas en los centros de protección de la Comunidad Valenciana, subyace que sufrieron distintos tipos de violencia en sus familias de origen cuando eran menores, es decir, antes de los 18 años y violencias de género e institucional siendo menores y mayores de edad.

\subsection{Violencias contra las menores en sus familias de origen}

En sus familias de origen vivieron la violencia de género que sus padres y padrastros ejercían sobre sus madres, la violencia física, psíquica, sexual y económica de sus padrastros contra ellas y negligencia por parte de sus madres, padres y padrastros. 


\subsubsection{Violencia de género contra sus madres}

Respecto a la violencia de género contra sus madres, nuestras protagonistas tan sólo poner de manifiesto los malos tratos físicos.

Mi padrastro pegaba a mi madre, mi hermano y yo la vimos sangrando en muchas ocasiones (HV6).

Incluso, señalan, que a pesar de los malos tratos físicos, la relación entre sus padres era buena y que, en su país, la violencia en las relaciones de pareja es normal, no como en España. Sin embargo, una de sus madres intentó divorciarse de su padre, aunque no lo consiguió.

La relación entre mis padres era buena, aunque a veces mi padre le pegaba a mi madre, pero en mi país esto es algo normal, no es como aqui. (...) Una vez mi madre decidió separarse de mi padre, en el juicio la abogada decidió que tres hijos se quedasen con mi madre y tres con mi padre. Pero mi padre dijo que no, que él no iba a separar a sus hijos, que nos quedásemos todos con él, porque él trabajaba y no nos iba a faltar nada. El juez al oir esto le dijo a mi madre que lo mejor sería que se fueran todos juntos a casa, porque pensaba que mi padre era un buen padre, trabajador, atento, y mis padres volvieron a casa juntos y al final no se separaron (HV5).

\subsubsection{Violencia intrafamiliar contra las menores física, psíquica, sexual y económica}

Sus padrastros también han ejercido distintos tipos de violencias contra ellas siendo menores de edad, por una parte violencia física.

Me pegaba a mí porque yo me volvi muy rebelde desde los más o menos trece años, porque yo estaba muy enfadada con mi mamá, porque yo le decía por qué no lo dejas y mi madre, pues tenía miedo y no quería (HV6).

Así mismo, sus padrastros no sólo las maltrataban físicamente, también ejercían violencia psicológica y sexual contra las mujeres migrantes institucionalizadas cuando eran pequeñas.

No tuve una infancia muy buena, no por mi madre, siempre por el mío padrastro. Siempre que venía con mi madre daba más atención a mí. A mí siempre me daba la paliza en un cuarto encerrada, siempre estaba encima de mí, me corría con el cinturón y me daba a las piernas, me hacia morados, fue una historia, uf, uf, uf... A mi abusaba, me maltrataba y cualquier cosa que pasaba siempre la culpable yo (HV2).

Por ello, nuestras protagonistas se ven obligadas a salir de casa sin tener dónde ir, a causa de la violencia, sobre todo, sexual, a la que las someten sus padrastros. Y, aunque, en algunos casos, se lo cuentan a sus madres, éstas no las creen.

Más llegó un momento que en fin, cuando llegó a los tres o cuatro años, madre yo me voy que llega el momento de ir. Yo sé que mi madre quería a él, no podía destruir la felicidad de mi madre. Junto los míos trapos, mi maleta y me voy a buscarme la vida donde sea (HV2).

Nunca le importó a mi madre lo que nos hacia él a nosotros, dijo que éramos unas mentirosas y que lo único que queríamos era apartarla de su marido y que ella nunca se iba a apartar. Nosotros por lo que optamos fue por irnos, por irnos y ponernos a trabajar (HV3).

En relación a la explotación y violencia económica, algunas de las mujeres migrantes cuando eran menores en su país y familia de origen tuvieron que dejar de ir al colegio siendo 
muy pequeñas porque sus padrastros las obligaban a trabajar para ganarse la comida.

\subsubsection{Negligencia por parte de sus madres y padres}

En las historias de vida de las menores analizadas también subyace la negligencia. Este es el caso de una de las mujeres institucionalizadas que tanto su madre como su padre se desentendieron cuando la mandaron a España a casa de la familia externa de su madre y nunca más se ocuparon ni preocuparon de ella.

Pues, no sé, yo tengo entendido que era para que viniera a estudiar aquí, a ver si podía labrar un futuro así estudiando y tal. Pero na, que la decisión la pidieron ellas y mi madre como la aceptó, pues nada me vine para aquí (HV1).

En este sentido, también es necesario reseñar que una de las menores se quedó embarazada con 13 años de un amigo de su padrastro 30 años mayor que ella y la obligaron a casarse con él.

Yo era virgen, yo tenía miedo porque era virgen, fue él el primero y fue que aconteció, la primera virginidad que había perdido y la primera que me quedé embarazada. Yo no lo busqué, yo al principio me miraba así, porque mi madre cuando yo era pequeña no me habia explicado nada sobre esto o lo otro. Me resultaba raro porque mi barriga comenzó a crecer. Cuando estaba de cuatro meses sentí una cosa en el estómago y fui al médico a ver qué era, me dijo que yo estaba embarazada. Yo embarazada, no puede ser, no ves que yo era pequeña, no lo sabía, era una chiquita (HV2).

Así, aun sin querer se vio obligada y no tuvo más remedio que vivir con su marido.

Llegué a vivir con él porque mi familia me obligó al estar embarazada. Ahi yo dije que yo no quiero, era obligada a casarme por lo civil, porque en el interior de Río es obligado casarte con el hombre que te ha dejado embaraza. Yo no quería pero mi familia me obligó, si no lo haces todos se botan contra ti. Y ahi nos casamos por lo civil, no por la iglesia, porque como era menor no podía casarme por la iglesia. Nos casamos y nos fuimos a vivir un tiempo (HV2).

Por su parte, la menor que fue mandada por su madre al estado español en busca de un futuro mejor sufrió diferentes tipos de violencia física y psíquica para obligarla a realizar las tareas domésticas y de cuidado de sus primas/os pequeños, por lo que no tenía tiempo para estudiar ni ir al colegio. Ello la llevó a desear la muerte e incluso intentó suicidarse en varias ocasiones.

Pero ni estudios ni mierdas, eso, para estar vamos, de chacha y de niñera, porque otra cosa (...). "Es que no vales pa na”, mi tía me decía, una vez, madre mía, cogió un cuchillo y quería darme, y yo le dije mátame, mejor para mí, así me alejo de vosotros. Y yo también he intentado tomarme cosas a ver si la palmaba, desde los 13 años (HV1).

De manera que a la primera oportunidad que tuvo se fue a vivir con un hombre y con 15 años ya estaba embarazada, poco después se separa, y como no tiene donde ir con un bebé muy pequeño, pide ayuda a los servicios sociales, desde donde, como todavía es menor de edad, se decreta una situación de desamparo, se procede a la tutela administrativa automática tanto de la madre como del bebé y se les ingresa en un centro de protección de mujeres.

\subsection{Violencia de género física, psíquica, sexual y económica en sus relaciones de pareja}

En las trayectorias vitales analizadas también aparecen distintos tipos de violencia que 
contra las mujeres migrantes institucionalizadas han ejercido sus parejas, es decir, violencia de género física, psíquica, sexual y económica tanto cuando eran menores como mayores de edad. En ocasiones, ellas se responsabilizan a sí mismas de los malos tratos sufridos.

Al principio la relación era bien y mal, habia días que él estaba bien conmigo, él siempre dándome cariño. Pero había días que estaba... me pegaba porque yo era siempre rebelde, le decía que me voy y me iba por ahí, y a él eso no le gustaba (HV3).

Terminé creyéndome todo lo que me decía, sin yo quererlo y sabiendo que no era cierto, me lo llegué a creer, me sentía culpable. Había algo dentro de mí que me decía que era mi culpa y que ahora tenía que aguantar todo. Como castigándome a mí misma (HV6).

Respecto a la violencia física, algunas veces consideran que no se trataba de malos tratos físicos serios y comparan la consideración de su país respecto este tipo de violencia con el Estado español.

Él no me pegaba de darme harto, sino que me daba una cachetada, pero dicen que un puñetito o una cachetada aquí en España ya es pegarle a alguien (HV3).

En otras ocasiones tras los malos tratos psíquicos y físicos los agresores les compraban algún regalo

El día a día eran gritos, eran empujones, alguna patada... y luego para contentarme me compraba algo, o sea, cuando me cascaba luego me compraba algo (HV6).

En este sentido, los malos tratos psíquicos consistían en gritos, insultos y amenazas, incluso de muerte. Pero demás, en las situaciones de irregularidad, los agresores las amenazaban diciéndoles que sí les denunciaban las iban a expulsar del país a ellas.

"Yo aquí tengo papeles y ya verás a quién van a hacer caso, a ti no". Él siempre me trataba con prepotencia porque tienen papeles y porque tienen dinero, según él. Siempre me decía que él tenía papeles y que yo era una pobre inmigrante, que nadie me iba a creer, ni ayudar ni nada, que me iban a devolver a mi país.

En referencia a la violencia sexual, incluso cuando todavía tenían 14 y 15 años, las acusaban de no querer quedarse embarazadas para irse con otros hombres, además de forzarlas y maltratarlas para mantener relaciones cuándo y cómo ellos quieren.

Sos mi mujer y me tenéis que cumplir como mujer, así que él me daba un puñete y listo. Yo tenía que hacer las cosas que él me decía, él me pegaba primero, para luego tener relaciones. Siempre ha sido así, por eso cuando me acuerdo me pongo mala... (HV3).

Pero que yo no las quería ver porque estás en el enamoramiento y tal, era que él quería hacer de pronto algo, que yo no quería. Un ejemplo, él quería algo en la cama, algo que yo no quería, ¿si me entiendes? entonces me insistía mucho y yo me sentía mal, me dolía y él insistía. Y al final hasta que lo logró no descansó, y yo también descansé, pero no lo hice por... sino porque me sentía obligada, manipulada (HV6).

Así mismo, las engañan respecto a los métodos anticonceptivos, para dejarlas embarazadas.

Entonces él se puso muy contento, y yo le preguntó que por qué se ponía tan contento si hemos utilizado condones. Me entró mucho miedo, porque tenía miedo de enfrentarme a mi mamá. Él se reía, entonces me dijo, "así como yo tengo miedo de perderte y tú ya tienes un 
hijo con el papá de (...), pues yo también quería que tuvieras un hijo mío, y he roto el condón” (HV6).

Nuestras protagonistas, al igual que les pasó a ellas, tienen miedo de que sus parejas y padres de sus hijas abusen de éstas, pues ellos piensan que les pertenecen.

Una mañana que estábamos echados los cinco le dijo a (...) ahi que tetingas, a mi hija le están saliendo los pechos, ahí que tetingas, dámelas para que yo las chupe. Oye, le dije yo, le estás faltando el respeto a mi hija. Y él dijo, pues de todas formas esas tetillas son mías y la otra ya se puso bravísima. La hija cuando escuchó lo que su padre le había dicho de sus tetas, sus pechos... Luego yo le dije que se disculpara con su hija y ya todo se arregló. (...) Me decía, mi papá es un loco, por dios, cómo me va a decir eso, soy su hija (HV3).

En relación con la violencia económica, sus parejas y padres de sus hijas/os se desentienden de sus necesidades económicas y de las de su descendencia cuando existe convivencia, no les dan dinero ni para comer ni tampoco pagan las pensiones de alimentos cuando se separan. Pero además, les molestan sus hijas/os y les maltratan, como hicieron con ellas sus padres y padrastros.

Por otra parte, los maltratadores son conscientes de que ellas les tienen que aguantar, porque están solas, no tienen dónde ir ni redes sociales y familiares que les puedan ayudar.

Yo decía me voy muchas veces, yo he hecho mi maleta y él se ponía a decirme riéndose "no te vas, a ver a dónde vas" y yo le decía que me iba a la calle, y me preguntaba "pero dónde, si no tienes a nadie” (HV5).

Otra de las cuestiones que les dificultaba escapar de la situación de violencia de género es el proyecto de vida e hijas/os en común con el agresor.

$Y$ yo en este tiempo estaba cegada y también estaba embarazada de él y yo pensaba en mi bebé, que no quería que creciese sin un padre... (HV5).

Yo siempre soñé con poder criar a mis hijos con su padre, que mis hijos no tuvieran que pasar por lo que yo he pasado. Pero es el destino de la vida que me jugó una mala pasada. Yo siempre he tenido esa mentalidad, por eso aguanté tantas cosas, que mis hijos tuvieran un padre, porque con tanta cosa que he pasado... pero escogí mal, escogi mal... (HV3).

Nuestras protagonistas no suelan denuncian la violencia de género en sus países de origen, aunque, en una ocasión lo hizo la madre de una de ellas, pero sin consecuencias, como señalan, en su país la violencia contra las mujeres está mucho más invisibilizada.

Él siempre me pegaba y siempre me daba en mis operaciones y me dejaba sin respiración de lo que él me daba siempre en la barriga. Porque yo estoy operada de la cesárea, a los tres niños los tuve con cesárea. Él siempre me pegaba ahí y un día me dejó medio muerta de lo que me golpeó. Me dejó sin respiración, por eso mi mamá agarró un palo, le dio y lo denunció. Pero allá las autoridades le dicen a uno que no vuelva a pasar, que se vaya pa su casa tranquilo y lo mandan tranquilo a casa, alli se tapa mucho más (HV3).

En ese sentido, una vez en el Estado español algunas mujeres migrantes denuncian a sus agresores.

Yo no podía hacer nada porque me pegaba, era muy agresivo. La última vez nos pegamos una paliza muy fuerte. La última paliza me dio un palo enorme, él me pegaba y yo le pegaba; luego me fui hacia la puerta, casi me mata... le puse una denuncia porque me habia 
agredido. Les enseñé las marcas en el cuerpo y puse una denuncia contra él (HV2).

Otras mujeres no quieren denunciar los malos tratos sufridos por parte de sus parejas porque se trata del padre de sus hijas/os.

Yo no quería denunciar porque es el padre de mi hijo y yo no podía hacer eso. Pero yo lo odiaba, ya cuando llegué a casa yo ya no quería hacer el amor con él. No quería nada, sólo quería irme lejos. Veía en la tele otra mujer muerta por violencia por su marido y yo decía, yo voy a ser una de esas y me estaba volviendo loca... Un día cuando él estaba durmiendo, cogí mis cosas y me fui. Le dije que me iba al doctor, pero en realidad me iba a poner la denuncia y al centro de mujeres (HV5).

Por su parte, algunas mujeres no sabían dónde acudir ni a quién pedir ayuda cuando sufrían violencia, no conocen la legislación al respecto ni sus derechos. Los maltratadores, incluso, en el juicio reconocen haberla maltratado y afirman que en su país un hombre mata a su mujer y no pasa nada.

A la juicio, al juez, y juez hablar a la marido, “ ¿tú verdad pegar ella?”, marido hablar "sí, no pasa nada, a la Marruecos a la hombre matar a la mujer y no pasa nada" y ya está.... (HV4).

\subsection{Violencia institucional}

Respecto a la violencia institucional, es necesario señalar la desprotección en la que están las menores en algunos de sus países de origen y la ayuda tan poco apropiada que se les ofrece en el Estado Español, especialmente cuando tienen cargas familiares en solitario. Así, una de las mujeres en su país además de iniciarse en el ejercicio de la prostitución siendo menor de edad, tuvo que renunciar a su descendencia, que acabó siendo adoptada de forma irregular.

Yo si tenía que mandar un poco de dinero a mi madre, un poco de dinero a mi familia para que mantuvieran a la niña. Yo no podía tener a la niña, entonces ella me dijo: "tú no te preocupes que yo voy a cuidarla como si fuera mi hija, no voy a pegarle y aquí no le va a faltar de nada" (HV2).

Por su parte, en el Estado español, a la menor inmigrante con cargas familiares que pide ayuda a los servicios sociales se la tutela al igual que a su descendencia se le ingresa en el centro de protección. Esto mismo ocurre con las mujeres mayores de edad en procesos de exclusión más o menos largos y más o menos rígidos. En los centros residenciales de servicios sociales ambas, menores y mayores, se tiene que ocupar de su descendencia en solitario, lo que imposibilita sus procesos formativos y laborales, ya que no puede compaginar el cuidado y la atención de un bebé con procesos formativos ni laborales. Así mismo, tiene que cumplir normas horarios y están controladas en todo momento por las profesionales. Pero, además, en el caso de las menores, cuando cumplen los 18 años se levanta de forma automática su tutela, pero no la de su descendencia, por lo que no podrá salir del centro con ella si no consigue un trabajo remunerado y vivienda adecuada, cosa difícil para las mujeres solas con cargas familiares, dada la dificultad de compaginar el trabajo reproductivo con el productivo, situación que se agrava con la falta de formación.

Estoy más asquea de estar aqui dentro, yo quiero mi libertad, pero es que esto es un agobio. Llegué aqui en junio, a los diecisiete años, hice los dieciocho y a lo mejor me quedo más tiempo, hablé con el asistente y según mi salida, se vería si yo sigo aquí más tiempo o no... (HV1). 


\section{DISCUSIÓN}

Las mujeres migrantes residentes en los centros de protección de mujeres de la Comunidad Valenciana, cuando eran menores de edad, sufrieron en su familia de origen la violencia de género que sus padres y padrastros ejercieron contra de sus madres, al igual que las mujeres no inmigrantes institucionalizadas cuando eran menores (Moriana, 2014).

Aunque, nuestras protagonistas, sólo ponen de manifiesto los malos tratos físicos, al igual que las mujeres no migrantes institucionalizas (Moriana, 2014) y señalan que en su país se trata de algo normal, diferenciando la situación con la Estado Español. La normalización de la violencia es una barrera cultural que impide o dificulta a las mujeres escapar de la violencia de género (Moriana, 2015). Efectivamente, en Estado español existe, además de una sensibilización importante bastante generalizada respecto al problema en las últimas décadas, una ley específica que penaliza a los agresores y protege y ayuda a las mujeres que sufren este tipo de violencia.

Tener que vivir la violencia que sufren sus madres tiene consecuencias negativas. Las investigaciones indican que el hecho de ser testigas/os de la violencia hacia sus madres tiene importantes repercusiones para el desarrollo evolutivo, emocional, cognitivo y social de las/os menores (Sepúlveda, 2006; Atenciano, 2009). Por ello, se ha empezado a reconocer que las y los menores hijas e hijos de las mujeres que sufren violencia también padecen la violencia de género. De hecho, en el Estado español se ha modificado la normativa para incluirles como víctimas.

Por otra parte, las menores que nos ocupan también han vivido en sus familias de origen la violencia por parte de sus padrastros. Algunos estudios afirman que un porcentaje elevado de menores hijas/os de mujeres que sufren violencia de género padecen, también, malos tratos por parte de la pareja de sus madres (Sepúlveda, 2006; Atenciano, 2009; Moriana, 2014). Así, nuestras protagonistas, al igual que las mujeres institucionalizadas no inmigrantes cuando eran menores (Moriana, 2014), han sufrido malos tratos físicos, psíquicos, sexual y económicos por parte de sus padrastros, que en algunos casos, también, han maltratado a sus madres.

Así, como hemos visto, en las historias de vida de las menores protagonistas de nuestro trabajo, subyace violencia sexual por parte padrastros, al igual que en las trayectorias vitales de las mujeres no migrantes institucionalizadas cuando eran menores (Moriana, 2014). Para Ventosa y López (2007), el incesto es la forma más severa de abusos sexuales a la infancia, pues implica la distorsión de los vínculos afectivos primarios y de los roles familiares y socava profundamente la capacidad de relación. Además, se produce dentro del núcleo de convivencia familiar, lo que hace a la víctima especialmente vulnerable e indefensa debido a la relación de dependencia material, afectiva y cognitiva del abusador.

Como las mujeres institucionalizadas no migrantes, cuando les cuentan a sus madres la violencia sexual a la que les han sometido sus padrastros, éstas no las creen (Cortes y Cartón 2000, citado en Guillén et al., 2002; Moriana, 2014). Así, la violencia las obliga a salir de casa de su familia de origen sin tener adonde ir, como también les pasa a las mujeres no migrantes cuando eran menores (Moriana, 2014).

Igual que las mujeres institucionalizadas no migrantes cuando eran menores (Moriana, 2014), no denuncian la violencia sexual que sufren. En este sentido, siguiendo el estudio del Secretariado General de Naciones Unidas sobre la violencia contra los niños de Fondo de las Naciones Unidas para la Infancia (UNICEF, 2014) en América Latina, el abuso sexual es el maltrato infantil menos denunciado, los agresores suelen ser varones y en 8 de cada 10 casos son los padres, esposos o parientes. 
Por otra parte, en las trayectorias vitales analizadas subyace el abandono de menores o negligencia por parte de sus madres y padres, igual que en el caso de las menores institucionalizadas no migrantes (2014). Cabe destacar que este fenómeno, cuando se produce en el entorno familiar, se considera un tipo de violencia o trato negligente (ONU, 2006); para algunas/os autoras/es es la forma más común de maltrato a las y los menores (López Martín, 2007; Torres, 2011).

Así, es evidente la negligencia por parte de sus madres y padres cuando se desentiende de su hija desde los 8 años que la mandan a España con su familia extensa, a pesar de que la estaban explotando y maltratando física y psíquicamente para que asumiese las tareas domésticas y de cuidado de sus familiares dependientes, lo que le imposibilitaba poder hacer los deberes e asistir a la escuela, como a otras mujeres no inmigrantes institucionalizadas cuando eran menores (Moriana, 2014). Ello ocasiona fracaso escolar, el abandono escolar por no tener tiempo para estudiar e ir a clase por tener que ocuparse de las tareas domésticas y de cuidado en sus familias es un factor de exclusión social de género (Moriana, 2014). Como señala Save the Children (2017), existen más probabilidades de que las niñas se queden completamente excluidas de la educación que los niños. Excluidas de la educación y atrapadas en el círculo vicioso de la pobreza estas menores ven sus derechos básicos quebrantados, su salud e incluso su vida.

Pero además, es una negligencia tremenda, obligar a una menor de 13 años a casarse con el hombre 30 años mayor que ella que la ha dejado embarazada. Pero también violencia institucional por parte del Estado por permitirlo. Save the Children (2017), ya ha puesto de manifiesto que muchas de esas niñas son forzadas por sus padres a casarse con hombres significativamente mayores que ellas. El matrimonio antes de los 18 años es una violación de los derechos de la infancia, y cada vez es ilegal en más países. Aun así, unos 40 millones de niñas adolescentes de entre 15 y 19 años están casadas o viven en pareja. Cada año, unos 15 millones más se casan antes de los 18, de los cuales 4 millones contraen matrimonio antes de los 15 años.

En relación con la violencia de género, nuestras protagonistas sufren, al igual que las mujeres no migrantes institucionalizadas cuando eran menores y mayores de edad, violencia física, psíquica, sexual y económica por parte de sus parejas y padres de sus hijas/os y en algunos casos, y al igual que las mujeres institucionalizadas no inmigrantes, ellas se consideran responsables (Moriana, 2014). Respecto a la violencia económica, sus parejas y padres de sus hijas/os no cumplen con el rol de proveedor de la economía doméstica cuando conviven ni pasan pensión de alimentos cuando dejan de hacerlo o no ha habido cohabitación, como ocurre con las mujeres menores no inmigrantes (Espinar, 2003; Moriana, 2014). Siguiendo a Melgar (2009), algunas investigaciones como la de Barnett afirman que, generalmente, los maltratadores se resisten más a pagar las pensiones de alimentos de sus hijas/os que los hombres que no lo son. El incumplimiento de este tipo de obligaciones, puede considerarse violencia económica. Siguiendo a Espinar (2003), en general, podría considerarse una forma de violencia psicológica y supone la asunción en solitario de las cargas familiares por parte de las mujeres menores. Pero además, ellas son las que se tienen que ocupar de realizar todo el trabajo doméstico y de cuidados, como en el caso de las mujeres no inmigrantes institucionalizadas (Moriana, 2014).

Por otra parte, y como bien saben los agresores, y señalan De Alencar (2013a) y Rodríguez Rodríguez (2014), las mujeres migrantes tienen que adaptarse a un nuevo país y afrontar el maltrato en un contexto desconocido, en el que muchas se encuentran aisladas.

Por otra parte, desde el ámbito de la atención social entendemos por violencia institucional la falta de apoyo o la ayuda inadecuada, que impide a las menores y mujeres escapar de las 
situaciones de violencia y que se protejan sus derechos humanos. Para comprender adecuadamente la violencia contra las mujeres tenemos que entender que se nutre también de violencias institucionales, de acciones u omisiones realizadas por el Estado y sus autoridades (Bodelón, 2014). La dimensión institucional de las violencias contra las mujeres es una de las cuestiones que la perspectiva feminista está incorporando al análisis de dicho fenómeno, porque es consciente del papel ambiguo del Estado en este tema. Todavía hoy en día al hablar de violencia contra las mujeres no se visibiliza suficientemente que estamos ante vulneraciones de derechos humanos de los que los Estados pueden ser directamente responsables, por acción u omisión. Así, una de las menores de esta investigación en su país siendo todavía menor de edad empezó a prostituirse para poder ganarse la vida y tuvo que dar a su hija en adopción irregular.

Diversas leyes latinoamericanas han concretado en definiciones de violencia institucional, así, por ejemplo, la Ley general de acceso de las mujeres a una vida libre de violencia de México (2007), en el artículo 18 define la violencia institucional "como los actos u omisiones de las y los servidores públicos de cualquier orden de gobierno que discriminen o tengan como fin dilatar, obstaculizar o impedir el goce y ejercicio de los derechos humanos de las mujeres así como su acceso al disfrute de políticas públicas destinadas a prevenir, atender, investigar, sancionar y erradicar los diferentes tipos de violencia". De esta manera, la violencia institucional no sólo incluye aquellas manifestaciones de violencia contra las mujeres en las que el Estado es directamente responsable por su acción u omisión, sino también aquellos actos que muestran una pauta de discriminación o de obstáculo en el ejercicio y goce de los derechos.

La violencia institucional puede desarrollarse en los diferentes campos donde actúa el Estado con relación a la prevención, atención, y reparación del daño. De modo que, los servicios sociales pueden configuran un espacio en el que se desempodera a las mujeres y en el que se establecen nuevas victimizaciones. Así, en nuestro país, la ayuda que muchas mujeres, tanto migrantes como no, obtiene es la institucionalización, ya que no tienen recursos económicos, ni redes sociales ni familiares que las puedan acoger. Como dice Subirats et al. (2004), el ingreso en los centros las separa bruscamente de su entorno más inmediato, desvinculándolas de dos ejes básicos de integración social: la esfera productiva (su relación con el mercado) en caso de tenerla, y las redes sociales y comunitarias.

Como en cualquier institución residencial, en los centros tienen que cumplir normas y horarios, además de convivir con más compañeras, al igual que las mujeres institucionalizadas no migrantes (Moriana, 2014). Los escasos estudios sobre los centros de protección de mujeres suscriben prácticamente todas las dificultades que para ellas supone el ingreso. Por una parte, los problemas de adaptación a la institución (Moriana, 2014). Pero, sobre todo, las investigaciones reseñan la excesiva regulación de la vida en los centros y la rigidez de las normas y horarios (Bravo, 2008; La Torre y Roig, 2011; De Alencar-Rodrigues y Cantera, 2013a; Moriana, 2014).

Así mismo, las mujeres menores inmigrantes institucionalizadas, al igual que las españolas, tienen dificultades importantes para formarse o realizar trabajo remunerado, porque las cargas familiares en solitario les impiden compaginar trabajo productivo y reproductivo (La Torre y Roig, 2011; Moriana, 2014). Como señala Save the Children (2017), las madres jóvenes tienen menos probabilidades de asistir a la escuela y más de tener que esforzarse para sostenerse económicamente. Esto las coloca a ellas y a sus hijos e hijas en riesgo de ser explotadas, tener mala salud y perpetuar los ciclos de pobreza. Así, con el agravante que cuando tienen que salir del centro, si no han conseguido tener una vivienda o ingresos económicos, ni las mujeres migrantes ni las españolas, puede salir de la institución 
de servicios sociales con su descendencia.

\section{CONCLUSIONES}

Aunque numerosas/os autoras/es señalan que las mujeres inmigrantes en el Estado español están en situación de vulnerabilidad ante la violencia de género (Cuadra, 2002; Gascón y Gracia, 2004; Montañés y Moyano, 2006; Federación de Mujeres Progresistas, 2007; Rodríguez, 2009; De Alencar et al., 2013b; López Merchán, 2013; Bello, 2015; Rodríguez Rodríguez, 2014), las mujeres migrantes institucionalizadas en los centros de protección de la Comunidad Valenciana sufren casi los mismos tipos de malos tratos que las mujeres no inmigrantes institucionalizadas cuando eran menores y mayores de edad en sus familias de origen y en sus relaciones de pareja, en sus respectivos países y en el Estado español, por lo que son prácticamente igual de vulnerables que las españolas sin recursos, pobres o en procesos de exclusión social.

Desde el enfoque interseccional, cuando las situaciones de violencia se relacionan con otros ejes de desigualdad como la clase social, es decir con pobreza y la exclusión social, aparece la encrucijada de violencia de la que las niñas y mujeres sin recursos no pueden escapar, porque la violencia les aboca a importantes procesos de exclusión y ésta, a su vez, les impide escapar de la violencia. Por ello, aunque la violencia contra las mujeres afecta a las mujeres y niñas de todos los países y de todas las clases sociales, no a todas les afecta de la misma manera.

Para Santa Cruz (2014), las representaciones textuales hacen referencia a la vulnerabilidad de las mujeres migrantes en el Estado español sin un cuestionamiento de los mecanismos generadores de desigualdad, discriminación y la responsabilidad de quien discrimina. Así, la categoría "mujer migrada" las construye y nombra como víctimas, sumisas e indefensas a las que hay que proteger invisibilizado sus historias, sus agencias y su heterogeneidad. Pero además, en España mucha gente cree que la culpa del aumento de la violencia la tienen las personas migrantes de países empobrecidos y atrasados. Sin embargo, Europa no están en absoluto exenta de esta problemática, los datos estadísticos son evidentes en este sentido.

Ahora bien, lo que sí marca una diferencia para las mujeres migrantes en el Estado español es la situación documental irregular, porque tienen muy complicado acceder al trabajo remunerado con los correspondientes derechos sociales y a la protección social. Así mismo, cuando denuncian la violencia sufrida obtienen autorización de residencia temporal provisional por razones humanitarias, aunque sin derecho a permiso de trabajo. Incluso, con sentencia judicial firme el permiso de residencia y de trabajo es provisional (para cinco años). Pero además, es necesario tener en cuenta las repercusiones concretas que puede tener una sentencia judicial firme desfavorable.

En algunos países la carencia de tutela obliga a las menores a iniciarse en la prostitución y a renunciar a su descendencia, en el Estado español, la protección de las menores y mujeres en procesos más o menos rígidos y más o menor largos de exclusión social, supone su institucionalización en centros de protección. Las mujeres con recursos no ingresan en los centros de servicios sociales cuando a causa de los malos tratos sufridos. De manera que, lo que las lleva a las mujeres a la institución no los malos tratos, sino la pobreza y la exclusión social.

En los centros conviven las mujeres en procesos de exclusión social españolas e inmigrantes y, como ya se ha señalado, a excepción de la situación documental, comparten prácticamente todas las desventajas que les impiden escapar de la violencia. Por ello, son 
muy vulnerables a la violencia, por ser pobres y excluidas y no sólo por ser migrantes, las mujeres migrantes de clases sociales medias y altas tampoco van a los centros ni son igual de vulnerables a la violencia contra las mujeres intrafamiliar y de género.

$\mathrm{El}$ ingreso en los centros revictimiza a las mujeres, la vida en ellos es difícil para todas. Allí tienen que cumplir normas, horarios, convivir con otras compañeras en situaciones igual de complicadas que ellas mismas, pierden su intimidad y son controladas en todo momento por las profesionales, que, aunque, ya suelen estar muy concienciadas con el tema de la violencia de género, no pasa otro tanto con las situaciones de pobreza, exclusión social y sus consecuencias. Pero también, porque tienen que asumir las cargas familiares en solitario, por lo que tanto las mujeres españolas como inmigrantes tienen muy difícil compaginar el trabajo productivo con el reproductivo, la situación se suele agravar debido a la escasa formación. Las mujeres en procesos de exclusión social que sufren violencia tienen derecho a ser ayudadas y protegidas donde decidan vivir y la administración la obligación de facilitarles las viviendas sociales, así se han comprometido en las leyes y estrategias estatales.

Para finalizar, es necesario volver a subrayar que para las mujeres tanto migrantes como españolas en situaciones de pobreza y exclusión social que sufren malos tratos en sus relaciones de pareja, la posibilidad de escapar de ella y el logro de su autonomía y empoderamiento está estrechamente relacionada con el acceso efectivo a todos recursos sociales que necesiten: económicos, de vivienda, formativos, laborales, sanitarios, colegios, escuelas infantiles, ludotecas, servicios sociales, atención psicológica, legal, etc. y con la eliminación de todos los obstáculos que imposibiliten la satisfacción real de todas sus necesidades, como el permiso de residencia y trabajo incondicional. Porque en la medida que la falta o la inadecuada ayuda pública impide o dificulta a las mujeres escapar de la violencia, sufren también revictimización o violencia institucional, en el sentido de permitida y tolerada por el Estado.

\section{BIBLIOGRAFÍA}

Atenciano, B. (2009) "Menores Expuestos a Violencia contra la Pareja: Notas para una Práctica Clínica Basada en la Evidencia". Clínica y Salud, n 20(3), pp. 261-272, en http:goo.gl/zbxcxf [consulta 03/10/2018].

Bello, A. (2015) "El contexto migratorio como determinante de la violencia de género en mujeres inmigrantes". Comité Económico Social de la Comunidad Valenciana, en http://goo.gl/tBC33k [consulta 29/09/2017].

Bodelón, E. (2014) "Violencia institucional y violencia de género". Anales de la Cátedra Francisco Suárez, Revista de filosofía jurídica y política, 48: 131-151, en https://goo.gl/YBEHhg [consulta 29/09/2017].

Bravo, C. (2008) "Menores víctimas de violencia de género: experiencia de intervención en un centro de acogida para familias víctimas de violencia de género". Intervención Psicosocial, 17(3): 337351.

Convención sobre los derechos del niño. Adoptada y abierta a la firma y ratificación por la Asamblea General en su Resolución 44/25, de 20 de noviembre de 1989, en https://goo.gl/M6o7eR [consulta 30/9/2017].

Cuadra, L. (2002) "La violencia en la mujer inmigrante", en Elósegui y Gaudó (Eds.), El rostro de la violencia: más allá del dolor de las mujeres. Barcelona, Icaria editorial, pp. 131-143.

De Alencar-Rodrigues, R. y Cantera, L. M. (2013a) "Intervención en violencia de género en la pareja. El papel de los recursos institucionales". Athenea Digital, 13(3): 75-100. DOI: https://doi.org/10.5565/rev/athenead/v13n3.1058 [consulta 03/10/2018].

De Alencar-Rodrigues, R.; Cantera, L. y Strey, M. (2013b) "Violencia de género en la pareja contra 
mujeres inmigrantes: un estado del arte”. La ventana, 37: 41-69, en https://goo.gl/4s8W1Z [consulta 29/09/2017].

Declaración sobre la eliminación de la violencia contra la mujer. Resolución de la Asamblea General de las Naciones Unidas 48/104, del 20 de diciembre de 1993 A/RES/48/104, d de 23 de febrero de 1994, en https://goo.gl/zh5vcW [consulta 03/10/2018].

Delegación del Gobierno para la Violencia de Género (2015) IX Informe Anual del Observatorio Estatal de Violencia sobre la Mujer, en https://goo.gl/jG5rxf [consulta 03/10/18].

Delegación del Gobierno para la Violencia de Género (2015) Macroencuesta de Violencia contra las mujeres. Ministerio de Sanidad, Servicios Sociales e Igualdad, en https://goo.gl/yHrVPs [consulta $03 / 10 / 2018]$.

Del Valle, T. (2001) “Asociacionismo y Redes de Mujeres. ¿Espacios puente para el cambio?”, Anuario de Hojas de Warmi. $\mathrm{N}^{\circ}$ 12. Facultad de Humanidades de Albacete. Universidad de Castilla- La Mancha, págs. 131-151, en https://goo.gl/bqC21F [consulta 29/09/2017].

Espinar, E. (2003) Violencia de género y procesos de empobrecimiento. Estudio de la violencia contra las mujeres por parte de su pareja o expareja sentimental (tesis doctoral). Alicante: Universidad de Alicante, en https://goo.gl/k1dvHT [consulta 29/9/2017].

Federación de Mujeres Progresistas (2007) "Mujeres inmigrantes y violencia de género. Aproximación diagnóstica a tres años de la existencia de la LEY de Medidas de Protección Integral contra la Violencia de Género", en https://goo.gl/V5H2R7 [consulta 29/9/2017].

Gascón, E. y Jorge G. (2004) "La problemática específica de las mujeres inmigrantes en procesos de violencia familiar de género", en https://goo.gl/2kewHN [consulta 29/9/2017].

Guillén, E.; Alemán, C; Arias, A.; De Lucas, F.; Pérez, D. (2002) "La detección de los casos de abuso sexual infantil desde los Servicios Sociales Generales: Principales dificultades y algunas sugerencias para su solución". IV Congreso de Trabajo Social. Los desafíos de la Violencia. Un compromiso del Trabajo Social para una sociedad más justa. Revistas Alternativas. Cuadernos de Trabajo Social, 10: 241-252. DOI.org/10.14198/ALTERN2002.10.17 [consulta 29/9/2017].

Hernández Pedreño, M. (Dir.) (2008) Exclusión Social en la Región de Murcia. Aproximación cualitativa y cuantitativa. Murcia: Universidad de Murcia.

Informe de la Cuarta Conferencia Mundial sobre la Mujer Beijing ,4 al 15 de septiembre de 1995. A/CONF.177/20/ Adoptada por la Asamblea General de las Naciones Unidas el 20 de noviembre de 1989, en https://goo.gl/H1k2nt [consulta 03/10/2018].

Izquierdo, M.J. (2004) "Del sexismo y la mercantilización del cuidado a su socialización: Hacia una política democrática del cuidado". SARE Emakunde, en https:/goo.gl/eD9GZm [consulta 29/9/2017].

La Torre, E. y Roig, A. (2011) "Los recursos de acogida temporal para mujeres sobrevivientes a situaciones de violencia machista intrafamiliar". Revista Crítica Penal y Poder, 1, pp. 88-116, en https://goo.gl/hbx29N [consulta 03/10/2018].

Ley Orgánica 1/2004, Ley Orgánica de Medidas de Protección Integral contra la Violencia de Género (LOE). BOE, $\mathrm{n}^{\circ} 313$, de 29 de diciembre de 2004, en https://goo.gl/8HTrpt [consulta 30/9/2017].

Ley 7/2012, de 23 de noviembre, de la Generalitat, Integral contra la Violencia sobre la Mujer en el Ámbito de la Comunitat Valenciana. Diario Oficial de la Generalitat Valenciana, no 6912, de 28 de noviembre de 2012, en https://goo.gl/kxKUKa [consulta 30/9/2017].

Ley General de Acceso de las Mujeres a una Vida Libre de Violencia del $1^{\circ}$ de febrero de 2007 de México (Última reforma DOF 22-06-2017), en https://goo.gl/aAdzRP [consulta 30/9/2017].

López Martín, E. (Dir.) (2007) "Violencia en el ámbito familiar contra menores, mayores y personas con discapacidad". Documento de Trabajo. Serie Familia y Sociedad, n 1, Madrid: CEU Ed.

Melgar, P. (2009) Trenquem el silenci: superación de las relaciones afectivas y sexuales abusivas por parte de las mujeres víctimas de violencia de género (tesis doctoral), Barcelona: Universitat de Barcelona, en https://goo.gl/xGXjBJ [consulta 29/9/2017].

Ministerio de Trabajo y Asuntos Sociales (2006) Maltrato infantil: detección, notificación y registro de casos, en https://goo.gl/FZHfS9 [consulta 03/10/2018].

Moriana, G. (2014) Entre la exclusión y violencia. Las mujeres institucionalizadas en los centros de protección de mujeres de la Comunidad Valenciana (tesis doctoral) accesible en, 
https://goo.gl/PfB9pe [consulta 29/9/2017].

Moriana, G. (2015) "La violencia contra las menores que inician su trayectoria vital en situación de vulnerabilidad social", Barataria. Revista Castellano-Manchega de Ciencias Sociales, 20: 185197. DOI: https://doi.org/10.20932/barataria.v0i20.21 [consulta 30/9/2017].

Montañés, P. y Moyano, M. (2006) "Violencia de género sobre inmigrantes en España: un análisis psicosocial", Pensamiento Psicológico, 2(6): 21-32, en https://goo.gl/jXXAZy [consulta 30/9/2017].

Organización de Naciones Unidas (2006) Informe de América Latina en el marco del Estudio Mundial de las Naciones Unidas. La violencia contra niños, niñas y adolescentes, en http://goo.gl/Kof8jX [consulta 30/9/2017].

Pujadas, J.J. (1992) El método biográfico, el uso de las historias de vida en las ciencias sociales. Cuadernos Metodológicos, $n^{\circ} 5$, Madrid: CIS.

Rodríguez, P. (2009) "Las violencias de género que sufren las mujeres migrantes", en M. J. Miranda; M.T. Martín-Palomo y B. Marugán (Eds.) Amor, razón, violencia. Madrid: Catarata, pp. 139-168.

Rodríguez Rodríguez, F. (2014) "La mujer extranjera en España y la violencia de género". Cuadernos de la Guardia Civil: Revista de seguridad pública, 49: 142-163, en https://goo.gl/1B5XA8 [consulta 30/9/2017].

Santa Cruz, Ú. (2014) "Violencias interseccionales y migración", en Congreso de Estudios poscoloniales. Feminismos transnacionales, hermenéutica y politicas de identidad. Buenos Aires, Argentina, en https://goo.gl/rNr2hd [consulta 30/9/2017].

Save de Children (2017) Infancias Robadas. Informe mundial sobre la infancia, en https://goo.gl/t7xhYC [consulta 29/9/2017].

Scott, J. (2003). "El género: Una categoría útil para el análisis histórico", en M. Lamas (Comp.). El género: la construcción cultural de la diferencia sexual. México, 265-302, en https:goo.gl/zpM8hA [consulta 29/9/2017].

Sepúlveda, Á. (2006) "La Violencia de Género como causa de Maltrato Infantil". Cuadernos Médico Forense, no 12 (43-44), pp. 149-164, en https://goo.gl/LzxYnd [consulta 30/9/2017].

Subirats, J.; Riba C.; Jiménez, L.; Obradors, A.; Jiménez, M.; Queralt, D.; Bottos, P.; Rapoport, A. (2004) Pobreza y exclusión social. Un análisis de la realidad española y europea. Colección de estudios sociales. Fundació La Caixa. $\mathrm{n}^{\circ} 16$.

Tójar, J. C. (2006) Investigación cualitativa: comprender y actuar. Col. Manuales de metodología de investigación educativa. Madrid: La Muralla.

Torres, T.G. (2011) El tratamiento educativo de la violencia en la educación infantil (tesis doctoral). Madrid: Universidad Complutense de Madrid, en https://goo.gl/3kWcYM [consulta 29/9/2017].

Ventosa M.; López, R. (2007) "Perfil clínico e intervención en salud mental con mujeres supervivientes a abuso sexual infantil intrafamiliar (incesto)", en J. Cobo Gómez (Coord.) Publicación oficial de la Sociedad Española de Psiquiatría Biológica, 14(4): 153-162.

UNICEF (2014) Ocultos a plena Luz, en https://goo.gl/xP2QGr [consulta 30/9/2017].

\section{Breve currículo:}

\section{Gabriela Moriana Mateo}

Doctora en estudios de Género; Socióloga y Trabajadora Social. Experiencia laboral: una larga práctica profesional en distintos centros de protección de mujeres en procesos de exclusión social y/o que sufren violencia de la Generalitat Valenciana. Actualmente, es directora y profesora del Máster Universitario en Género y Políticas de Igualdad y profesora del Departamento de Trabajo Social y Servicios Sociales de la Universidad de Valencia. Las principales líneas de investigación son la exclusión social desde la perspectiva de género, los recursos y servicios sociales para mujeres y la violencia contra las mujeres y de género. 